Article

\title{
Crossed intergrowth triggered TS-2 microsphere: Formation mechanism, modification and catalytic performance
}

\author{
Hao Xu, Wenwen Tian, Liping Xu, Xin Jin, Teng Xue, Li Chen, Mingyuan He, Peng Wu * \\ Shanghai Key Laboratory of Green Chemistry and Chemical Processes, School of Chemistry and Molecular Engineering, East China Normal University, \\ Shanghai 200062, China
}

\section{A R T I C L E I N F O}

\section{Article history:}

Received 21 September 2019

Accepted 16 November 2019

Published 5 July 2020

\section{Keywords:}

Titanosilicate

TS-2 microsphere

Crossed intergrowth

Ammoximation reaction

Post-treatment

\begin{abstract}
A B S T R A C T
TS-2 microspheres, consisting of intergrown primary nanocrystals, was prepared by controlling the synthetic parameters. The effects of the amount of quaternary ammonium cations as structure-directing agent, $\mathrm{H}_{2} \mathrm{O} / \mathrm{Si}$ ratio, the presence of alcohol and the temperature were carefully investigated on the crystallization process. The high alkalinity was proved to be highly important for the preservation of the microsphere morphology initially formed, due to the unique intergrown stacking style. An alkali treatment with the aqueous solution of structure-directing agent, organic amine and ammonium salt and subsequent $\mathrm{Na}^{+}$ion-exchange were performed to enhance the catalytic activity of TS-2 microsphere in the cyclohexanone ammoximation reactions, with both the conversion and selectivity higher than $99 \%$. In the continuous reaction, the TS- 2 microspheres exhibited to be durable catalyst with potential application in industrial ammoximation processes.
\end{abstract}

(C) 2020, Dalian Institute of Chemical Physics, Chinese Academy of Sciences. Published by Elsevier B.V. All rights reserved.

\section{Introduction}

TS-1, as the first invented titanosilicate [1], has achieved great success in the field of liquid-phase selective oxidation reactions, such as alkene epoxidation [2], phenol hydroxylation [3], ammoximation of ketones [4] and oxidative desulfurization [5]. The usage of $\mathrm{H}_{2} \mathrm{O}_{2}$ as the oxidant makes the TS- 1 catalyzed reactions only produce $\mathrm{H}_{2} \mathrm{O}$ as the sole byproduct, which significantly improves the backwardness of traditional oxidation reactions. This environment-friendly titanosilicate $/ \mathrm{H}_{2} \mathrm{O}_{2}$ reaction system triggered the development of more titanosilicates with various structural topologies, including TS-2 [6], Ti-Beta [7], Ti-MOR [8], Ti-MWW [9], etc. Among them, TS-2, with the topology of MEL, showed very comparable catalytic properties as TS-1 titanosilicate due to similar building units in framework structure [10-12]. Both TS-1 and TS-2 belong to the pentasil family, having the 10-membered ring (10R) pore channels with the size of $0.51-0.55 \mathrm{~nm}$. TS-1, with the topology of MFI, possessed intersecting straight and sinulsoidal 10R pore channels, while the two intersecting 10R pore channels in TS-2 are both straight. Normally, the crystal size of TS-2 is much smaller, which favors the diffusion of substrates in catalyzing oxidation reactions. However, the nanosized crystals would cause difficulties in the separation of TS-2 nanoparticals from both the synthetic mixtures and the reaction systems.

In terms of industrial application, the zeolite powder catalysts are always embedded in a matrix using organic or inorganic binders to form granules, spheres or extrudates $[13,14]$. Although most of the binders are chemically inert, they cannot be absolutely inactive in particular for the $\mathrm{H}_{2} \mathrm{O}_{2}$-involved oxidations and they may also block the zeolite micropores, and thus the intrinsic catalytic activity and selectivity would be lowered.

\footnotetext{
* Corresponding author. Tel/Fax: +86-21-62232292; E-mail: pwu@chem.ecnu.edu.cn

This work was supported by the National Natural Science Foundation of China $(21533002,21603075,21872052)$ and the China Ministry of Science and Technology (2016YFA0202804).

DOI: 10.1016/S1872-2067(20)63546-X | http://www.sciencedirect.com/science/journal/18722067 | Chin. J. Catal., Vol. 41, No. 7, July 2020
} 
In-situ transformation of $\mathrm{SiO}_{2}$ or $\mathrm{SiO}_{2}-\mathrm{MO}_{x}(\mathrm{M}=$ metal) microsphere into crystalline monolithic zeolite and assembling the nanosized zeolite crystals into microspheres with the assistant of surfactant or by controlling the synthetic process, are alternative methods to produce industrial shaped catalysts $[15,16]$. The amount of alkaline structure-directing agent (SDA) and the control of crystallization condition such as temperature and time are critical for the preservation of the microsphere morphology in the in-situ transformation of $\mathrm{SiO}_{2}$ or $\mathrm{SiO}_{2}-\mathrm{MO}_{x}$ precursors into crystalline monolithic zeolites. Triblock copolymers, like P123 or F127, were reported to favor the self-assembly of TS-1 nanoparticles into microspheres with high mechanical strength [17]. In addition to this, adding inorganic additive of $\mathrm{H}_{2} \mathrm{O}_{2}$ also produced microsized TS- 1 aggregations, triggered by the formation of $\mathrm{Ti}-\mathrm{OOH}$ in the synthetic gel [18]. By simply controlling the synthetic conditions is also possible to induce the formation of microsized aggregates. The aggregations of uniform Beta nanocrystals were obtained by a dense-gel synthesis using steam-assisted conversion [19]. However, this one-step aggregation method without binders may have mechanical strength problems due to weak intercrystal interactions.

In spite of the unique catalytic performance of titanosilicates in the liquid-phase oxidation reactions, the diffusion constrains of micropores cannot be ignored in processing bulky substrates, especially for TS- 1 and TS- 2 titanosilicates with medium-size 10R pore channels. Introducing mesopores into the framework of micropore titanosilicate could enhance the accessibility of active sites and increase the catalytic activity. Although crystallizing titanosilicates with the assistant of hard or soft template are effective in creating mesopores, the alkaline treatment has the advantages of low cost and is also easily handled $[20,21]$. However, the dissolution of framework silicon is random and hard to control [22,23]. Thus, the porogen agents like organic amines were included in the alkaline treatment to control the kinetic rate of silicon dissolution [24,25]. The dissolution-recrystallization of titanosilicates with quaternary ammonium hydroxide, typically the SDA for synthesizing the specific titanosilicate, induced intracrystalline mesopores and achieved higher yield and better crystallinity than that treated by inorganic alkaline solution like $\mathrm{NaOH}$. However, the quaternary ammonium cations are usually too large to enter the inside of titanosilicate framework, which decreased the efficiency of this dissolution-recrystallization method. The addition of ammonium salt has been reported to improve the efficiency due to smaller molecular size of $\mathrm{NH}_{4}{ }^{+}$, which could diffused into the framework of titanosilicates and compensate with $\mathrm{OH}^{-}[26,27]$.

On the other hand, the micro-environment of Ti species also affected the catalytic performance of titanosilicates. F- ions have been introduced into the framework of Ti-MWW to form Si-F bonds and made the Ti ions more electropositive and simultaneously the framework more hydrophobic, which increased the catalytic performance in the alkene epoxidation reactions $[28,29]$. Besides, the closed Ti site can be transformed into six-coordinated open Ti site by introducing the organic amine ligand of piperidine (PI) and increased the catalytic activity in the alkene epoxidation reactions, due to more reactivity of octahedral coordinated open Ti sites [30]. Moreover, the presence of PI could also compensated with the acidity of silanols and increase the selectivity of epoxides. The presence of acidic silanols in titanosilicates could also be selectively eliminated by alkali ion-exchange, resulting in improved catalytic activity in the ammoximation reactions [31]. Thus, both the pore structure and micro-environment of Ti active site should be considered when constructing a novel titanosilicate catalyst.

In the present study, a TS- 2 microsphere catalyst was prepared by controlling the synthetic conditions and its unique crossed intergrowth structure was characterized. Additional mesopores were also created by a combined treatment of organic amine and ammonium salt. The framework hydrophilicity was further enhanced by controlled $\mathrm{Na}^{+}$ion-exchange. The catalytic performance of the obtained hydrophobic TS-2 microsphere were evaluated in the ammoximation of cyclohexanone in both batchwise and continuous reactors.

\section{Experimental}

\subsection{Synthesis of TS-2 catalysts}

TS-2 microsphere was synthesized using tetraethylorthosilicate (TEOS) as the silica source and tetra- $n$-butyltitanate (TBOT) as the Ti source. Typically, TEOS was added into the aqueous solution of tetrabutylammonium hydroxide (TBAOH) as SDA and was kept stirring at room temperature for $45 \mathrm{~min}$ to achieve complete hydrolysis. Then, the mixture of TBOT and isopropanol (1:32 in molar ratio) was added dropwise to the above mixture and kept stirring for another $30 \mathrm{~min}$ to hydrolyze TBOT. The alcohols were then removed from the mixture by heating at elevated temperature of $353 \mathrm{~K}$ to give the final composition of $1 \mathrm{SiO}_{2}$ : 0.3 TBAOH : $1 / 40$ TBOT : $20 \mathrm{H}_{2} \mathrm{O}$. Finally, the synthetic gel was transferred into the autoclave and heated statically at $443 \mathrm{~K}$ for $72 \mathrm{~h}$. The TS- 2 microsphere was recovered by filtration, washing and drying at $353 \mathrm{~K}$ overnight, denoted as MS-TS-2. The occluded organic SDA was removed by calcination in air at $823 \mathrm{~K}$ for $6 \mathrm{~h}$.

For control experiments, nanosized TS- 2 catalyst, denoted as Nano-TS-2 was also synthesized using the same method, with a gel composition of $1 \mathrm{SiO}_{2}: 0.18 \mathrm{TBAOH}: 1 / 40$ TBOT : 20 $\mathrm{H}_{2} \mathrm{O}$. The obtained solid product was recovered by centrifugation. TS-2-K and TS-2- $\mathrm{NH}_{3}$ were synthesized with the composition of $1 \mathrm{SiO}_{2}: 0.18 \mathrm{TBAOH}: 1 / 40$ TBOT : $20 \mathrm{H}_{2} \mathrm{O}: 0.02 \mathrm{KOH}$ and $1 \mathrm{SiO}_{2}: 0.18 \mathrm{TBAOH}: 1 / 40$ TBOT $: 20 \mathrm{H}_{2} \mathrm{O}: 0.18 \mathrm{NH}_{3} \cdot \mathrm{H}_{2} \mathrm{O}$, respectively. TS-2-80 was synthesized using the same composition as Nano-TS-2 with an additional aging process at $353 \mathrm{~K}$ for $24 \mathrm{~h}$ before being heated at elevated temperature of $443 \mathrm{~K}$.

\subsection{Post-modification of MS-TS-2}

MS-TS-2 was treated with a aqueous solution of PI, TBAOH and $\mathrm{NH}_{4} \mathrm{Cl}$, with the composition of $1 \mathrm{SiO}_{2}: 0.03 \mathrm{TBAOH}: 0.01$ PI : $0.07 \mathrm{NH}_{4} \mathrm{Cl}: 10 \mathrm{H}_{2} \mathrm{O}$ at $443 \mathrm{~K}$ for $24 \mathrm{~h}$. The solid product was collected by filtration, washing and drying and was denoted as MS-TS-2-PI. The organic species were then removed by 
calcination at $823 \mathrm{~K}$ for $6 \mathrm{~h}$.

To further increase the hydrophobicity of calcined MS-TS-2-PI, $\mathrm{Na}^{+}$ion-exchange was performed in $0.1 \mathrm{M} \mathrm{NaNO}_{3}$ aqueous solution with a solid-to-liquid weight ratio of $1: 100$ at room temperature for $24 \mathrm{~h}$. The solid product was collected by filtration, washing and drying and was denoted as MS-TS-2-PI-Na.

For control experiment, the commercial TS- 1 with the Si/Ti ratio of 32 was purchased from Zhejiang Taide New Materials Co. Ltd.

\subsection{Characterization method}

The structures of both microsphere and conventional nanosized TS-2 catalysts were characterized by X-ray diffraction patterns collected on a Rigaku Ultima IV X-ray diffractometer with $\mathrm{Cu} K_{\alpha}$ radiation $(\lambda=1.5406 \AA)$ with a scan speed of $10^{\circ}$ $\mathrm{min}^{-1}$. The morphology of TS- 2 catalysts were determined by Scanning electron microscopy (SEM) images measured by a Hitachi S-4800 microscope. The intergrowth of MS-TS-2 was characterized by the transmission electron microscopy (TEM) images, collected by a Tecnai $\mathrm{G}^{2} \mathrm{~F} 30$ transmission electron microscope at $300 \mathrm{kV}$. The $\mathrm{Si} / \mathrm{Ti}$ and $\mathrm{Si} / \mathrm{Na}$ ratio were measured by inductively coupled plasma emission spectrometry (ICP-AES) on a thermo IRIS intrepid II XSP atomic emission spectrometer. The samples were dissolved in the HF aqueous solution before measurements. The nitrogen sorption isotherms were measured at $77 \mathrm{~K}$ on a Quantachrome iQ-MP gas adsorption analyzer. Before the nitrogen absorption, the TS-2 samples were dehydrated at $573 \mathrm{~K}$ at least for $3 \mathrm{~h}$. The coordination state of Ti ions were determined by the UV-visible (UV-vis) spectra, recorded on a Shimadzu UV-2700 spectrophotometer using $\mathrm{BaSO}_{4}$ as a reference. The Fourier transform infrared (FT-IR) spectra were collected on a Nicolet Nexus 670 FT-IR spectrometer operated at a spectral resolution of $2 \mathrm{~cm}^{-1}$ in absorbance mode. Self-supporting pellets made of the sample was set in a quartz cell and sealed with $\mathrm{CaF}_{2}$ or $\mathrm{KBr}$ windows. The cell was connected to a vacuum system. After the sample was dehydrated at $723 \mathrm{~K}$ for $2 \mathrm{~h}$, the FT-IR spectra in the hydroxyl stretching vibration region were then measured at room temperature. For pyridine adsorbed IR spectra, the pretreated self-supported wafer was exposed to a pyridine vapor at $298 \mathrm{~K}$ for $20 \mathrm{~min}$, and then the physisorbed and chemisorbed pyridine was removed by evacuation at $423 \mathrm{~K}$ for $10 \mathrm{~min}$. Solid-state ${ }^{29} \mathrm{Si}$ MAS NMR experiments were performed on a VARIAN VNMRS-400WB spectrometer using $\left[\left(\mathrm{CH}_{3}\right)_{3} \mathrm{SiO}\right]_{8}$ $\mathrm{SiO}_{12}$ as the chemical shift reference at a frequency of 79.43 $\mathrm{MHz}$, a spinning rate of $3 \mathrm{kHz}$, and a recycling delay of $60 \mathrm{~s}$.

\subsection{Catalytic reactions}

The catalytic performance was evaluated in the ammoximation of cyclohexanone. In the batchwise reaction, $100 \mathrm{mg}$ of catalyst, $12 \mathrm{~g}$ of tert-butanol $(t-\mathrm{BuOH}), 10 \mathrm{mmol}$ of cyclohexanone and $15 \mathrm{mmol}$ of $\mathrm{NH}_{3} \cdot \mathrm{H}_{2} \mathrm{O}$ (25 wt\%) were mixed in a three-necked flask, equipped with a condenser. The reaction mixture was stirred and heated to desired temperature, where
$1.4 \mathrm{~mL} \mathrm{H}_{2} \mathrm{O}_{2}$ (30 wt.\%) was added with a constant speed in a period of $1 \mathrm{~h}$. And the reaction was kept for another $1 \mathrm{~h}$ before being cooled down. The liquid phase was then separated by centrifugation and analyzed on a gas chromatograph (Shimadzu 2014) equipped with an Rtx®-Wax capillary column (30 m × $0.25 \mathrm{~mm} \times 0.25 \mu \mathrm{m}$ ) and FID detector.

The continuous reaction was performed in a $160 \mathrm{~mL}$ glass slurry reactor equipped with a glass sand filter and a magnetic stirrer. Typically, $3 \mathrm{~g}$ catalyst, $86 \mathrm{~mL} t$-BuOH (99\%) and $25 \mathrm{~mL}$ $\mathrm{H}_{2} \mathrm{O}$ were added in the reactor and heated to $349 \mathrm{~K}$ under stirring. The mixture of cyclohexanone and $85 \% t$ - $\mathrm{BuOH}$ (volume ratio of $1: 3.4$ ) and $30 \mathrm{wt} \% \mathrm{H}_{2} \mathrm{O}_{2}$ were fed into the reactor separately using micro-pumps with a rate of 90 and $21 \mathrm{~mL} \mathrm{~h}^{-1}$, respectively. In the meantime, $\mathrm{NH}_{3}(>99.5 \%)$ was charged into the reaction system using a mass flowmeter with a constant speed of $150 \mathrm{~mL} \mathrm{~min}^{-1}$. The reaction mixture overflowed from the outlet filter and the catalyst powder remained in the reactor. The products were analyzed on the same gas chromatograph described above.

\section{Results and discussion}

\subsection{Preparation and characterization of microsphere TS-2 catalyst}

The TS-2 catalyst was synthesized using the same method as the conventional nanoszied TS-2 zeolite, but with distinct synthetic composition. Larger amount of SDA was needed in the synthesis of TS-2 with a microsphere morphology. In spite of this, the XRD patterns of MS-TS-2 and Nano-TS-2 were almost identical, showing the characteristic diffraction peaks of MEL topology (Fig. 1(a) and (b)). No diffraction peak was found at $2 \theta=9.05^{\circ}$ and $24.05^{\circ}$, indicating the pure MEL phase for both TS- 2 zeolites free of MFI impurity. However, significant difference was observed in the SEM images between MS-TS-2 and Nano-TS-2 (Fig. 2). Nano-TS-2 was composed of 250-300 nm nanocrystals, which were the aggregates of much smaller primary particles (Fig. 2(a)). In contrast, MS-TS-2 possessed the microspheres of 8-10 $\mu \mathrm{m}$, consisting of intergrown primary crystals as shown by the images under higher magnification. The primary particles of Nano-TS-2 and MS-TS-2 were compa-

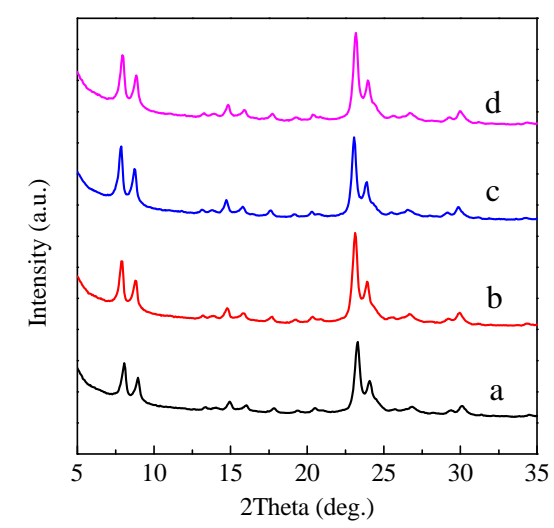

Fig. 1. XRD patterns of Nano-TS-2 (a), MS-TS-2 (b), MS-TS-2-PI (c), and MS-TS-2-PI-Na (d). 

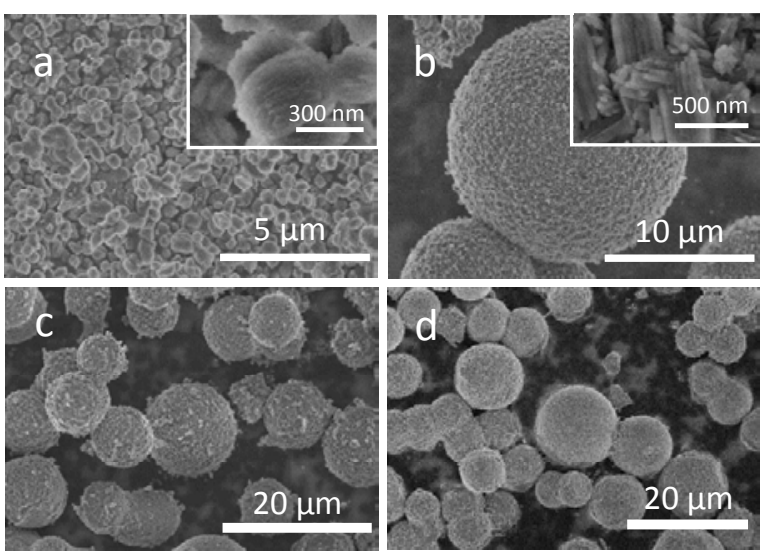

Fig. 2. SEM images of Nano-TS-2 (a), MS-TS-2 (b), MS-TS-2-PI (c) and MS-TS-2-PI-Na (d). The insets show the primary crystals on the surface of aggregates or microshperes.

rable in size, consistent with the XRD patterns having the diffraction reflections with similar peak width.

The sole difference in synthesizing MS-TS-2 and Nano-TS-2 was the amount of SDA. Thus, the amount of SDA was carefully investigated in the TBAOH/Si ratio range of $0.12-0.40$ (Fig. 3), keeping other crystallization conditions constant. With the increase of TBAOH/Si ratio from 0.12 to 0.18 , both the sizes of the primary and secondary particles decreased (Fig. 3(a) and (b)). The morphology changed from uniform ellipsoids of around $3 \mu \mathrm{m}$ to irregular nanosized (250-300 nm) aggregates. This is probably because the increase of SDA favored the formation of crystal nucleus and suppressed their growth into larger ones. Further increasing the SDA amount to TBAOH/Si > 0.25 , the microspheres $(8-10 \mu \mathrm{m})$ composed of intergrown TS-2 nanocrystals appeared (Fig. 3(c)). With the TBAOH/Si reached 0.4 , the primary crystals became even thinner and the crossed intergrowth was more obvious (Fig. 3(d)). However, the MS-TS-2 microspheres synthesized at $\mathrm{TBAOH} / \mathrm{Si}=0.3$ showed the most well-shaped sphere appearance (Fig. 2(b)). On the other hand, the $\mathrm{H}_{2} \mathrm{O} / \mathrm{Si}$ ratio could also affect the concentration of SDA and then the morphology of TS-2 zeolites (Fig. 4). The primary particle size increased with the $\mathrm{H}_{2} \mathrm{O} / \mathrm{Si}$
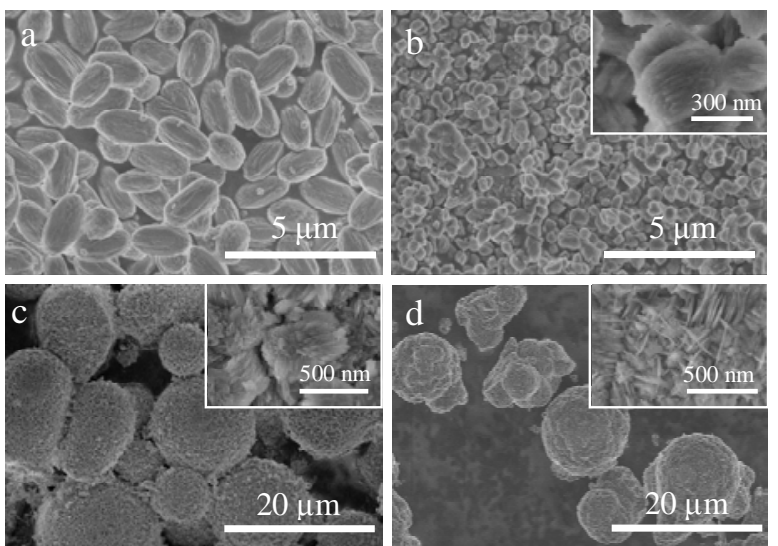

Fig. 3. SEM images of the TS- 2 samples synthesized with a $\mathrm{SDA} / \mathrm{SiO}_{2}$ ratio of 0.12 (a), 0.18 (b), 0.25 (c), and 0.40 (d). Other conditions: $\mathrm{SiO}_{2}$ : $\mathrm{TiO}_{2}: \mathrm{H}_{2} \mathrm{O}=1: 1 / 40: 20,443 \mathrm{~K}$, static. ratio increasing from 5 to 25 , while no significant change can be observed by further increasing the $\mathrm{H}_{2} \mathrm{O} / \mathrm{Si}$ ratio. Microsphere morphology only formed with the $\mathrm{H}_{2} \mathrm{O} / \mathrm{Si}$ ratio varying in the range of 15-25. The one synthesized with $\mathrm{H}_{2} \mathrm{O} / \mathrm{Si}$ ratio of 5 possessed the smallest primary and secondary particles (Fig. 4(a)), probably due to an extremely high SDA concentration. Higher $\mathrm{H}_{2} \mathrm{O} / \mathrm{Si}$ ratio $(>35)$ broke the microspheres to separated nanosized aggregates and eliminated the intergrowth phenomena (Fig. 4(d)-(f)).

The higher SDA concentration has been proved to be crucial for the formation of microsphere TS-2 zeolite, compared to the nanosized TS-2. Normally, a higher SDA concentration leads to a high alkalinity. It was measured that the synthetic gel of Nano-TS-2 possessed a $\mathrm{pH}$ value of $\sim 10.5$, while that for MS-TS-2 was high as $\sim 11.7$. To further confirm this, additional alkaline agent of $\mathrm{NH}_{3} \cdot \mathrm{H}_{2} \mathrm{O}$ or $\mathrm{KOH}$ was added into the synthetic gel of conventional Nano-TS-2 to achieve the same $\mathrm{pH}$ value $(\sim 11.7)$ of the synthetic gel for microsphere MS-TS-2. As shown Fig. 5(a) and (b), the microspheres, consisting of intergrown primary crystals, with the size around 8-10 $\mu \mathrm{m}$ was observed by increasing the alkalinity, although the microspheres were not as uniform as those in MS-TS-2. High alkalinity would also induce the formation of larger amount of nucleus, which may be responsible for the microspheres morphology. Thus, additional aging process at $353 \mathrm{~K}$ was performed to increase the nucleus amount before crystallizing the synthetic gel of Nano-TS-2 at elevated temperature. Only nanosized aggregations appeared in Fig. 5(c), indicating that the larger amount of nucleus were not the reason for the formation microsphere morphology. Thus, suitable $\mathrm{pH}$ of the synthetic gel was critical for the crossed intergrowth of TS-2 nanosized primary crystals. However, the usage of $\mathrm{NH}_{3} \cdot \mathrm{H}_{2} \mathrm{O}$ or $\mathrm{KOH}$ induced the formation of anatase phase [32], indicated by the obvious adsorption
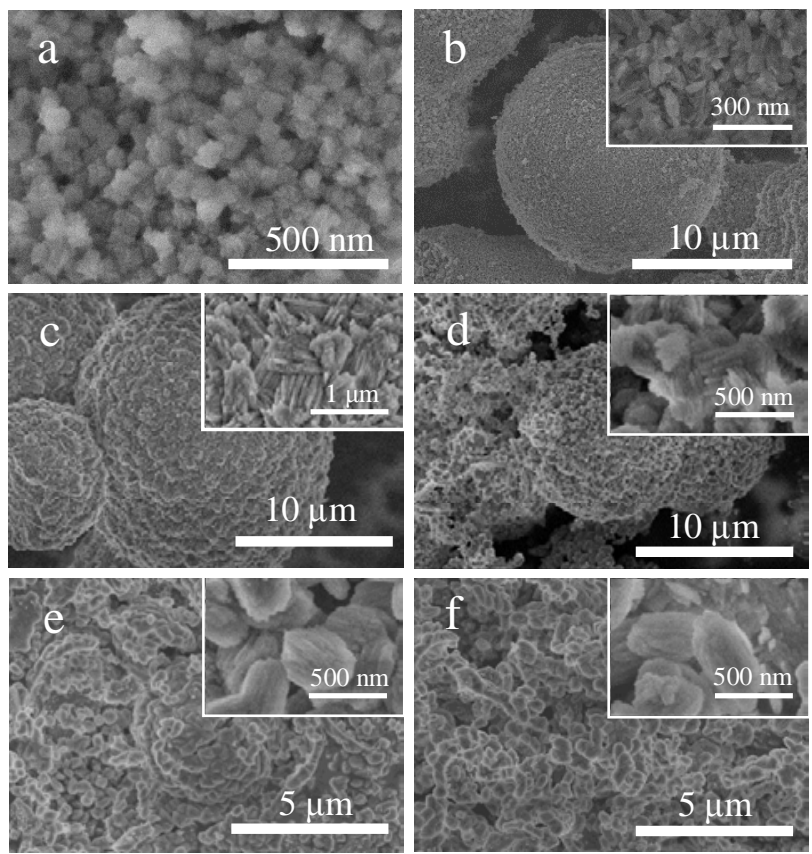

Fig. 4. SEM images of TS- 2 samples synthesized with a $\mathrm{H}_{2} \mathrm{O} / \mathrm{SiO}_{2}$ ratio of 5 (a), 15 (b), 25 (c), 35 (d), 50 (e), and 70 (f). Other conditions: $\mathrm{SiO}_{2}$ : $\mathrm{TiO}_{2}: \mathrm{TBAOH}=1: 1 / 40: 0.30,443 \mathrm{~K}$, static. 

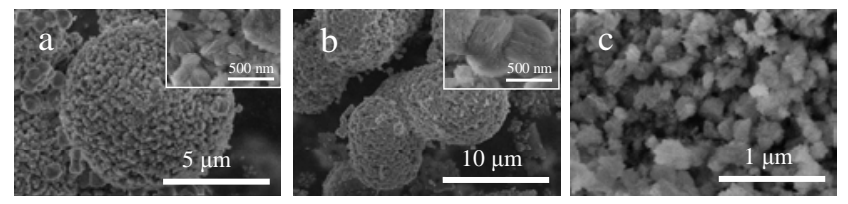

Fig. 5. SEM images of the TS-2 samples synthesized with SDA/Si ratio of 0.18 with further addition of $\mathrm{NH}_{3} \cdot \mathrm{H}_{2} \mathrm{O}(\mathrm{a}), \mathrm{KOH}$ (b) or aged at $353 \mathrm{~K}$ for $24 \mathrm{~h}$ (c). Other synthetic conditions: $\mathrm{SiO}_{2}: \mathrm{TBAOH}: \mathrm{TBOT}: \mathrm{H}_{2} \mathrm{O}=1: 0.18$ $: 1 / 40: 20,443 \mathrm{~K}$, static.

band around $320 \mathrm{~nm}$ (Fig. S1(b) and (c)). Moreover, other synthetic parameters were also investigated. Decreasing the crystallization temperature to $393 \mathrm{~K}$ retarded the crystallization process and a longer time of $12 \mathrm{~d}$ was needed for full crystallization, but it did not affect the microsphere morphology (Fig. S2(a)). The diffraction peaks were much broader due to the presence of smaller primary particle size (Fig. S3(a)). To investigate whether the presence of Ti ions favored the formation of microspheres, a Ti-free S-2 silicalite was synthesized. The morphology and the crystallinity of S-2 were comparable to those of MS-TS-2 (Fig. S2(b) and Fig. S3(b)), meaning that the presence of $\mathrm{Ti}$ ions hardly affect the crystallization process. Once the synthetic gel of MS-TS-2 was crystallized under dynamic condition, MFI impurity appeared and ill-formed aggregates were observed (Fig. S2(c) and Fig. S3(c)). The presence of alcohols has been reported to be of high importance in synthesizing titanosilicates [33]. The alcohols including ethanol and butanol formed in the hydrolysis of TEOS and TBOT were then kept in the synthetic gels, which induced the formation of MEL and MFI composite (Fig. S2(d) and Fig. S3(d)). Thus, the successful synthesis of MS-TS-2 highly depended on suitable alkalinity ( $\mathrm{pH} \sim 11.7$ ) and static crystallization conditions free of alcohol.

The formation mechanism of microsphere MS-TS-2 was further investigated by comparing the crystallization process between MS-TS-2 and Nano-TS-2, tacked in detail by XRD and SEM techniques. Fig. S4 and Fig. S5 show the XRD patterns of solid products recovered from the synthetic mixture of MS-TS-2 and Nano-TS-2 at different crystallization time. After 2 h, only amorphous phase was observed for the MS-TS-2 system and very weak diffraction peaks attributed to MEL phase appeared at $3 \mathrm{~h}$. Then the crystallinity was enhanced with prolonging crystallization time, and a fully crystallized MS-TS-2 was obtained at $24 \mathrm{~h}$. In the contrast, the diffraction peaks due to MEL phase appeared after $5 \mathrm{~h}$ for Nano-TS-2, meaning slower crystallization rate. The change of the relative crystallinity and solid product yield depending on the crystallization time for MS-TS-2 and Nano-TS-2 is shown in Fig. 6. Nano-TS-2 showed a relatively slow crystallization speed in the first $8 \mathrm{~h}$ compared to MS-TS-2. However, the solid product yield of MS-TS-2 was lower than that of Nano-TS-2, especially in the first $8 \mathrm{~h}$, although the yield of MS-TS- 2 could reach $90 \%$ after $72 \mathrm{~h}$. These phenomena are supposed to be closely related to the high alkalinity of MS-TS-2 synthetic system, which caused the dissolution speed faster than that of recrystallization speed in the initial crystallization process. The SEM images gave direct information of the morphology change in the whole crys-
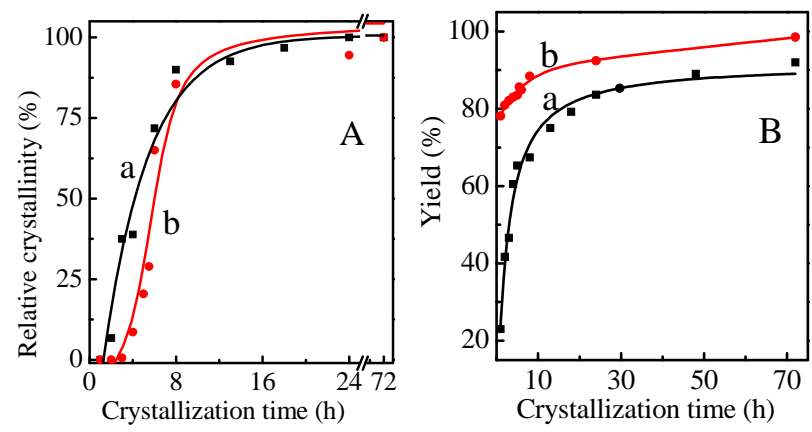

Fig. 6. Dependence of relative crystallinity (A) and solid product yield (B) on the time for MS-TS-2 (a) and Nano-TS-2 (b) crystallized at $443 \mathrm{~K}$.

tallization. For MS-TS-2, amorphous microspheres appeared in the very beginning of crystallization process (Fig. 7(a)). After 2 $h$, small-sized amorphous oligomers were observed on the surface (Fig. 7(b)). The TEM images revealed that the amorphous oligomers also appeared inside the microspheres (Fig. 7(b)). More and more oligomers were observed with the crystallization going on (Fig. 7(c)). These oligomers are supposed to be the precursor of the primary nanosized crystals. Cross-intergrown primary nanocrystals appeared at $5 \mathrm{~h}$ and these primary crystals showed a very thin nanosheet morphology. With the crystallization time was extended to $72 \mathrm{~h}$, the size of primary crystals increased and intergrown nanorods were obtained. The size of microspheres was almost the same in the whole crystallization process. Although the amorphous microspheres also formed in the beginning of Nano-TS-2 crystallization process (Fig. S6(a) and (b)), the microspheres were broken with the primary nanocrystals appeared (Fig. S6(c)). Thus, only nanosized aggregates were obtained after $72 \mathrm{~h}$. The intergrowth morphology was further confirmed by TEM images (Fig. 8). The MEL nano-plates intercrossed vertically due to identical pore channels along $a$ and $b$ axes. The unique cross-intergrowth in MS-TS- 2 is considered as the direct reason for the well-preserved microspheres in the whole crystallization. And high alkalinity favored the cross-intergrowth style. The occlusion of Ti ions were also investigated in the whole crystallization process (Fig. S7). The Ti content increased with the crystallization time, in good consistent with the crystallinity curves, meaning the Ti ions were incorporated into the structure with crystallization of TS- 2 zeolite. Based on these characterizations described above, the possible crystallization mech-
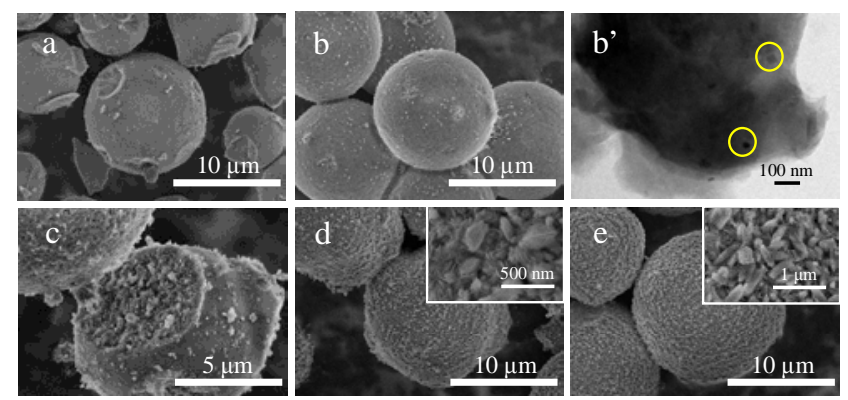

Fig. 7. SEM images of MS-TS-2 crystallized for 1 (a), 2 (b), 3 (c), 5 (d), and $72 \mathrm{~h}(\mathrm{e})$. TEM image (b') showing the inner part of the corresponding microshperes (b). 

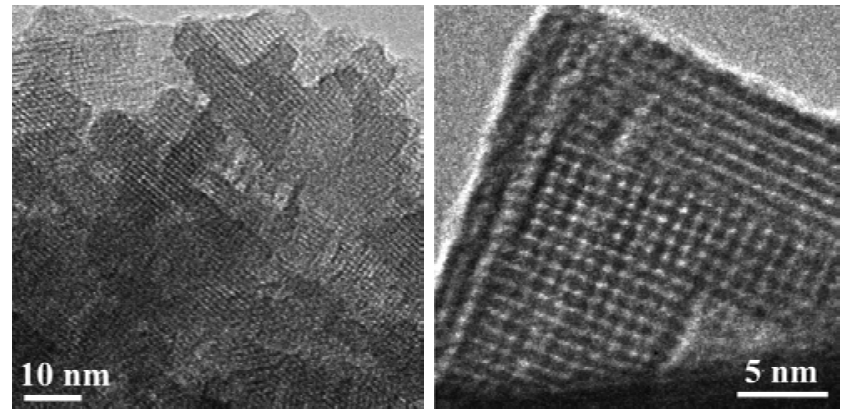

Fig. 8. TEM images of MS-TS- 2 crystals.

anism of microsphere MS-TS-2 and nanosized aggregations Nano-TS-2 was described in Scheme 1. Initially, the Si and Ti species self-assembled to amorphous microspheres, and then oligomers formed in both the inner part and outer surface of the microspheres, which served as the precursors of the primary crystals. However, with the crystallization going on, the primary crystals tended to form different stacking style under different $\mathrm{pH}$ environments. In the media with a higher $\mathrm{pH}$ value, the primary crystals tended to cross-intergrow and form a strong intercrystal interaction, which favored the preservation of initially formed microsphere morphology. In the contrast, the lower $\mathrm{pH}$ value induced the parallel stacking style, and then the intension between crystals broken the microspheres, resulting in naonosized aggregates.

The obtained MS-TS-2 and Nano-TS- 2 showed distinct $\mathrm{N}_{2}$ sorption isotherms (Fig. 9(a) and (b)). The corresponding surface area and pore volume determined by $\mathrm{N}_{2}$ sorption isotherms are shown in Table 1. MS-TS-2 showed higher surface area and external surface area than Nano-TS-2, while the total volume and mesopore volume of MS-TS-2 were lower. However, the comparable micropore volume indicated the two TS-2 zeolites possessed similar crystalline primary particles. The different stacking style possibly induced the formation of different intercrystal mesoporosity. The pore distribution curves revealed that the mesopore size was larger for MS-TS-2 compared to Nano-TS-2 due to the cross-intergrown primary crystals. The coordination state of Ti ions were also comparable for the two TS-2 materials indicated by the similar UV-vis spectra (Fig. 10(a) and (b)). The presence of the sole adsorption band at $220 \mathrm{~nm}$ suggested the $\mathrm{Ti}$ ions were all tetrahedrally coordinated in the TS-2 framework [34].

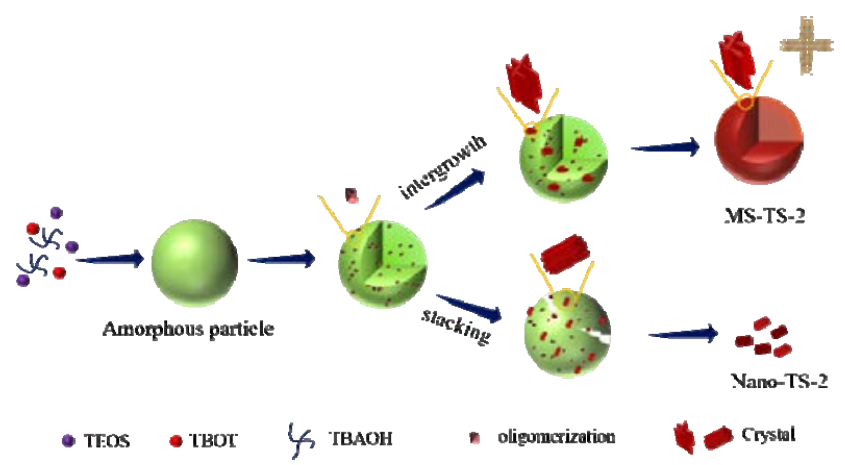

Scheme 1. Possible crystallization mechanism of MS-TS-2 and Nano-TS-2.
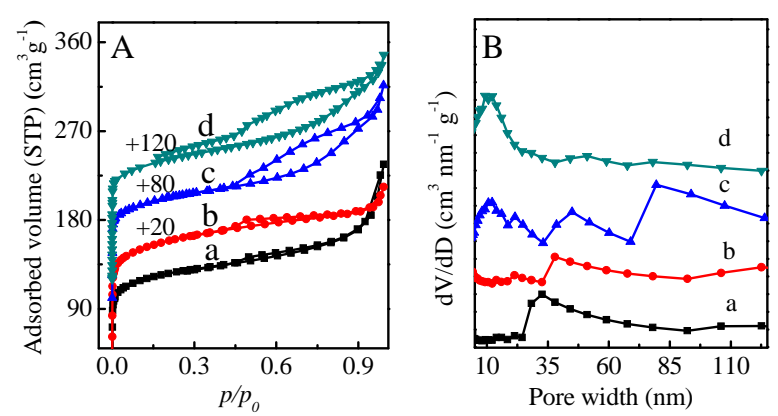

Fig. 9. $\mathrm{N}_{2}$ adsorption-desorption isotherms (A) and pore size distribution (B) of Nano-TS-2 (a), MS-TS-2 (b), MS-TS-2-PI (c), and MS-TS-2-PI-Na (d).

Table 1

Physicochemical properties of different TS-2 zeolites.

\begin{tabular}{lcccccc}
\hline \multirow{2}{*}{ Catalyst } & \multicolumn{2}{c}{ Surface area $\left(\mathrm{m}^{2} \mathrm{~g}^{-1}\right)$} & & \multicolumn{3}{c}{ Pore volume $\left(\mathrm{cm}^{3} \mathrm{~g}^{-1}\right)$} \\
\cline { 2 - 3 } \cline { 5 - 7 } & $S_{\text {BET }^{\mathrm{a}}}$ & $S_{\text {ext }} \mathrm{b}^{\mathrm{b}}$ & & $V_{\text {total }}$ & $V_{\text {mico }}{ }^{\mathrm{b}}$ & $V_{\text {meso }}{ }^{\mathrm{c}}$ \\
\hline Nano-TS-2 & 420 & 134 & & 0.44 & 0.13 & 0.31 \\
MS-TS-2 & 467 & 148 & & 0.30 & 0.14 & 0.16 \\
MS-TS-2-PI & 418 & 176 & & 0.36 & 0.12 & 0.24 \\
MS-TS-2-PI-Na & 417 & 157 & & 0.34 & 0.12 & 0.22
\end{tabular}

a Specific surface area (BET) measured by $\mathrm{N}_{2}$ adsorption at $77 \mathrm{~K}$.

${ }^{\mathrm{b}}$ Given by $t$-plot method.

c $V_{\text {meso }}=V_{\text {total }}-V_{\text {micro. }}$

\subsection{Post-treatment and catalytic performance of microsphere TS-2 catalyst}

Although TS-2 catalyst has been reported to give similar catalytic activity to TS-1 in the phenol hydroxylation and alkene epoxidation reactions, TS-2 showed lower activity than that of TS-1 in the ammoximation of cyclohexanone [35-37], which is an important reaction producing cyclohexanone oxime, the key bulk chemical in nylon- 6 manufacturing industry. Thus, the two different TS-2 catalysts were firstly evaluated in the batchwise ammoximation of cyclohexanone reaction. As shown in Table 2, with comparable Si/Ti ratio, Nano-TS-2 showed slightly higher cyclohexanone conversion than that of MS-TS-2 (19.2\% vs $18.6 \%$ ), and the selectivity to the cyclohexanone oxime were

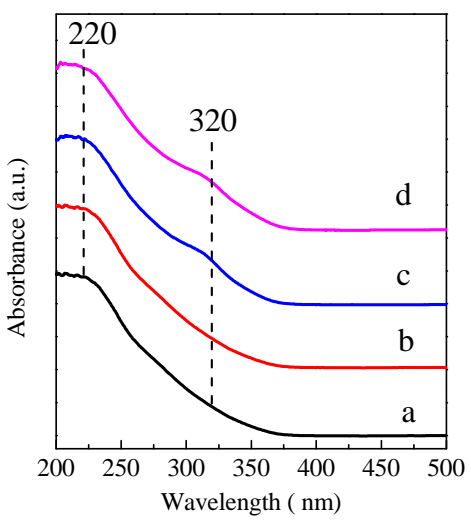

Fig. 10. UV-vis spectra of Nano-TS-2 (a), MS-TS-2 (b), MS-TS-2-PI (c), and MS-TS-2-PI-Na (d). 
Table 2

The results of cyclohexanone ammoximation over different TS-2 catalysts ${ }^{\text {a. }}$.

\begin{tabular}{lcccc}
\hline Sample & $\mathrm{Si} / \mathrm{Ti}^{\mathrm{b}}$ & $\mathrm{Si} / \mathrm{Na}^{\mathrm{b}}$ & Con. (\%) & Sel. (\%) \\
\hline Nano-TS-2 & 60 & - & 19.2 & 84.9 \\
MS-TS-2 & 63 & - & 18.6 & 86.6 \\
MS-TS-2-PI & 69 & - & 91.4 & 97.0 \\
MS-TS-2-PI-Na & 70 & 746 & 99.5 & 99.7 \\
\hline
\end{tabular}

a Reaction conditions: cat. $100 \mathrm{mg}, t$-BuOH $12 \mathrm{~g}$, cyclohexanone 10 mmol, $\mathrm{NH}_{3} \cdot \mathrm{H}_{2} \mathrm{O}$ (25 wt\%) 15 mmol, $\mathrm{H}_{2} \mathrm{O}_{2}$ (30 wt.\%) $12.5 \mathrm{mmol}, 343 \mathrm{~K}, 2$ h.

b Molar ratio determined by ICP analysis.

lower than $90 \%$ for both of the two TS- 2 catalysts, which were much lower than that of TS-1 in reported literatures [36,37]. In spite of the comparable catalytic activity of MS-TS-2 and Nano-TS-2 catalysts, the microsphere MS-TS-2 would show significant advantages in the separation of solid products from both the synthetic and reaction mixture and was more likely served as industrial catalyst. Thus, post-modifications were performed on MS-TS-2 to increase the catalytic activity.

An aqueous solution of $\mathrm{PI}, \mathrm{TBAOH}$ and $\mathrm{NH}_{4} \mathrm{Cl}$ was firstly used to create mesopores in the micropore framework of TS-2. TBAOH, as the typical SDA for TS-2, would direct the dissolution-recrystallization process [38], while $\mathrm{NH}_{4} \mathrm{Cl}$ with smaller-size cation could entered into the inner part of the framework and then introduced more $\mathrm{OH}^{-}$ions inside the titanosilicate framework to create mesopores [26,27]. The PI molecules were employed to protect the outer surface of titanosilicate and to prevent excess desilication [25]. Then, an $\mathrm{Na}^{+}$ion-exchange was performed to remove the hydroxyl-related acid sites [31]. The MS-TS-2-PI and MS-TS-2-PI-Na samples showed more intense diffraction peaks than those of the pristine MS-2-TS-2 titanosilicate (Fig. 1(b) and (c)). This was induced by the dissolution-recrystallization process, which enhanced the crystallinity. Moreover, the microsphere morphology was well-preserved in the procedure of post-treatments (Fig. 2(c) and (d)), indicating that the alkali solution hardly changed the intergrowth style of MS-TS-2. Obvious hysteresis loop appeared in the $\mathrm{N}_{2}$ sorption isotherms after the treatment with $\mathrm{PI}$, TBAOH and $\mathrm{NH}_{4} \mathrm{Cl}$ solution (Fig. 9(A)), indicating the successful introduction of mesopores. Correspondingly, additional mesopores with the size of $\sim 10 \mathrm{~nm}$ was observed in the pore distribution curve of MS-TS-2-PI (Fig. 9Bc). Thus, MS-TS-2-PI exhibited larger external surface area (176 vs $148 \mathrm{~m}^{2} \mathrm{~g}^{-1}$ ) and mesopore volume ( 0.24 vs $\left.0.16 \mathrm{~cm}^{3} \mathrm{~g}^{-1}\right)$ than those of the pristine MS-TS-2 (Table 1). The micropore volume was very close for MS-TS-2 and MS-TS-2-PI, meaning the protective desilication process hardly affected the crystallinity of the TS-2 framework, which was in good agreement with XRD patterns. And the subsequent $\mathrm{Na}^{+}$ion-exchange preserved the newly formed mesopores, with slightly lower external surface area and comparable mesopore volume as MS-TS-2-PI. However, minor adsorption band appeared at $\sim 320 \mathrm{~nm}$ in the UV-vis spectra, revealing that the present of anatase phase (Fig. 10(c) and (d)). Small amount of Ti active sites leached from the framework during the alkali treatment and $\mathrm{Na}^{+}$ion-exchange processes, which has been reported in previous literatures [27]. The IR spectra (Fig. 11) in

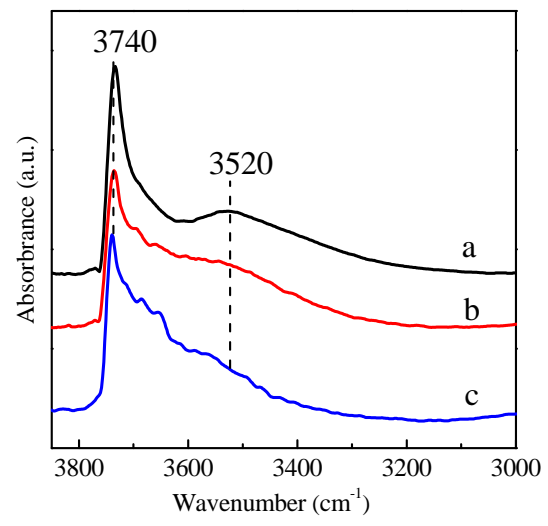

Fig. 11. IR spectra of MS-TS-2 (a), MS-TS-2-PI (b) and MS-TS-2-PI-Na (c) in the hydroxyl stretching vibration region.

the hydroxyl region revealed the variation of silanols in the post treatments of MS-TS-2 zeolite. The pristine MS-TS-2 zeolite showed intense vibration band at $3740 \mathrm{~cm}^{-1}$, attributed to external Si-OH groups, and the broad band around $3520 \mathrm{~cm}^{-1}$, assigned to internal hydroxyl nests (Fig. 11a) [39]. The desilication process by the mixture of $\mathrm{PI}, \mathrm{TBAOH}$ and $\mathrm{NH}_{4} \mathrm{Cl}$ induced the decrease of both external and internal $\mathrm{Si}-\mathrm{OH}$ groups, revealed by the decrease of the two bands around 3740 and 3520 $\mathrm{cm}^{-1}$, because the dissolution-recrystallization process directed by TBAOH repaired some of the framework defects (Fig. 11(b)). The Si-OH groups could be further removed by $\mathrm{Na}^{+}$ ion-exchange, by replacing them with $\mathrm{Si}-\mathrm{O}-\mathrm{Na}$ groups (Fig. 11(c)). The pyridine (Py) adsorbed IR spectra were also recorded to reveal the change of Lewis acidity. The vibration band around 1446 and $1604 \mathrm{~cm}^{-1}$, assigned to Py molecules interacted with the Lewis acid sites [40]. The intensity of 1446 and $1604 \mathrm{~cm}^{-1}$ band suffered a significant decrease after the alkali treatment (Fig. 12), due to the decrease of $\mathrm{Si}-\mathrm{OH}$ groups as revealed by Fig. 10. The $\mathrm{Na}^{+}$ion-exchange could further decrease the intensity of the two Lewis acidity-related bands, indicating that the $\mathrm{Na}^{+}$ion-exchange effectively eliminates Lewis acid sites.

Both the MS-TS-2 and MS-TS-2-PI-Na were then evaluated

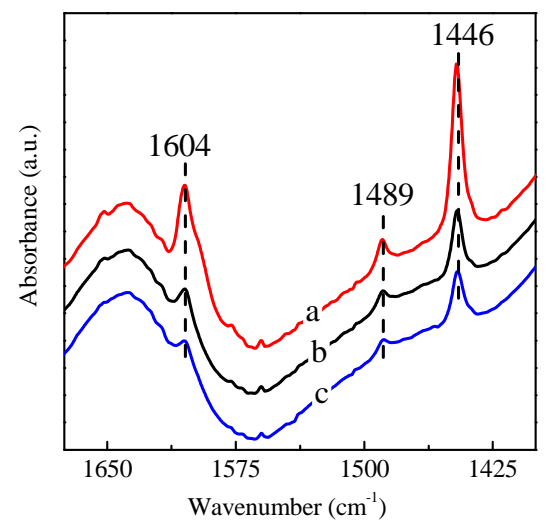

Fig. 12. IR spectra of MS-TS-2 (a), MS-TS-2-PI (b) and MS-TS-2-PI-Na (c) after pyridine adsorption at $298 \mathrm{~K}$ and then desorbed at $423 \mathrm{~K}$ for $10 \mathrm{~min}$. 

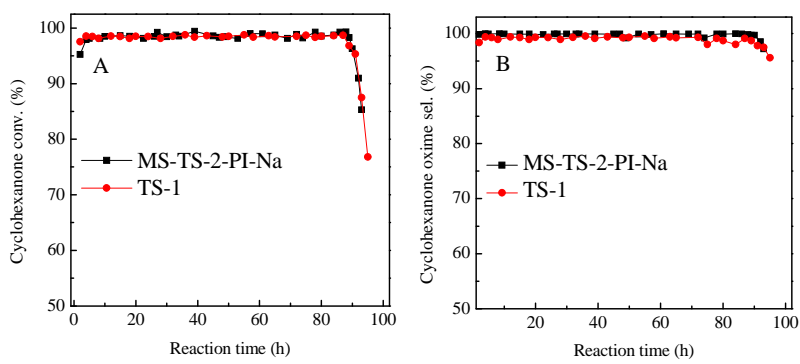

Fig. 13. The cyclohexanone conversion and oxime selectivity in a continuous slurry reactor using MS-TS-2-PI-Na and TS-1 as the catalysts. Reaction conditions: cat. $3 \mathrm{~g}, \mathrm{H}_{2} \mathrm{O}_{2}$ (30 wt\%) $21 \mathrm{~mL} \mathrm{~min}^{-1}, \mathrm{NH}_{3} 150 \mathrm{~mL}$ $\mathrm{min}^{-1}$, the mixture of cyclohexanone and $t$-BuOH (15 wt\%) $90 \mathrm{~mL} \mathrm{~min}^{-1}$, $349 \pm 1 \mathrm{~K}$.

in the batchwise ammoximation of cyclohexanone. The Si/Ti ratio of MS-TS-2-PI and MS-TS-2-PI-Na were slightly higher than that of the pristine MS-TS-2, meaning that the post-treatments only resulted in minor Ti leaching. However, the conversion of cyclohexanone was largely enhanced to 91.4\% from $18.4 \%$ of pristine MS-TS-2 and the selectivity for cyclohexanone oxime was also increased from $86.6 \%$ to $97 \%$, after the treatment of alkali mixture. The catalytic performance could be further enhanced after the $\mathrm{Na}^{+}$ion-exchange, with both the conversion and selectivity $>99 \%$, due to the elimination of acidic silanols. The high catalytic activity of MS-TS-2-PI-Na encouraged us to evaluate its performance in the continuous ammoximation reaction, which imitated the industrial process. As shown in Fig. 13, the catalytic performance of MS-TS-2-PI-Na was compared with industrial TS-1 in the continuous reaction and they showed comparable life time of $\sim 90 \mathrm{~h}$. The microsphere morphology and crystallinity of were well preserved for MS-TS-2-PI-Na in the continuous ammoximation reaction (Fig. S8). The deactivation was possibly induced by the carbon deposition and the minor change of $\mathrm{Ti}$ environment in the alkaline reaction system, as revealed by the TG analysis (Fig. S9) and UV-vis spectra of the used MS-TS-2 (Fig. S10). These results indicated that the microsphere MS-TS-PI-Na was potential to serve as an industrial catalyst for the cyclohexanone ammoximation reaction.

\section{Conclusions}

An intergrowth triggered microsphere TS- 2 catalyst was prepared by controlling the synthetic parameters. High alkalinity was crucial for the preservation of initially formed microspheres due to the special intergrowth stacking style. Moreover, the static crystallization condition and the alcohol-free crystallization environment were also proved to be important for the formation of microsphere morphology. The alkali treatment with the mixture of $\mathrm{PI}, \mathrm{TBAOH}$ and $\mathrm{NH}_{4} \mathrm{Cl}$ and the subsequent $\mathrm{Na}^{+}$ion exchange was performed to increase the catalytic performance of MS-TS-2. The conversion and selectivity could reach $>99 \%$ for post-treated MS-TS-PI-Na catalyst and the life time was comparable as industrial TS- 1 in the ammoximation of cyclohexanone reaction. This microsphere TS-2 catalyst is potential as an industrial catalyst.

\section{References}

[1] G. Perego, M. Taramasso, B. Notari, US 4410501, 1983.

[2] M. G. Clerici, G. Bellussi, U. Romano, J. Catal., 1991, 129, 159-167.

[3] A. Tuel, S. Moussa-Khouzami, Y. Ben Taarit, C. Naccache, J. Mol. Catal., 1991, 68, 45-52.

[4] T. Tatsumi, N. Jappar, J. Catal., 1996, 161, 570-576.

[5] S. Du, F. Li, Q. Sun, N. Wang, M. Jia, J. Yu, Chem. Commun., 2016, 52, 3368-3371.

[6] J. S. Reddy, R. Kumar, P. Ratnasamy, Appl. Catal., 1990, 58, L1-L4.

[7] A. Corma, M. A. Camblor, P. Esteve, A. Martinez, J. Perezpariente, J. Catal., 1994, 145, 151-158.

[8] P. Wu, T. Komatsu, T. Yashima, J. Phys. Chem., 1996, 100, 10316-10322.

[9] P. Wu, T. Tatsumi, Chem. Commun., 2002, 1026-1027.

[10] A. Tuel, Y. Ben Taarit, Appl. Catal. A, 1993, 102, 69-77.

[11] J. S. Reddy, S. Sivasanker, Catal. Lett., 1991, 11, 241-244.

[12] M. Sasidharan, R. Kumar, Catal. Lett., 1996, 38, 251-254.

[13] L. Itani, V. Valtchev, J. Patarin, S. Rigolet, F. F. Gao, G. Baudin, Microporous Mesoporous Mater., 2011, 138, 157-166.

[14] C. Feng, T. Liu, P. Wang, L. Pan, W. Li, Q. Yuan, Z. Feng, Modern Chem. Ind., 2019, 39(8), 185-190.

[15] M. A. Uguina, D. P. Serrano, G. Ovejero, R. Van Grieken, M. Camacho, Appl. Catal. A, 1995, 124, 391-408.

[16] L. Yu, J. Gong, C. Zeng, L. Zhang, Ind. Eng. Chem. Res., 2012, 51, 2299-2308.

[17] Z. Wang, L. Xu, J. Jiang, Y. Liu, M. He, P. Wu, Microporous Mesoporous Mater., 2012, 156, 106-114.

[18] Z. Shan, Z. Lu, L. Wang, C. Zhou, L. Ren, L. Zhang, X. Meng, S. Ma, F. Xiao, ChemCatChem, 2010, 2, 407-412.

[19] K. Möller, B. Yilmaz, R. M. Jacubinas, U. Müller, T. Bein, J. Am. Chem. Soc., 2011, 133, 5284-5295.

[20] H. C. Xin, J. Zhao, S. T. Xu, J. P. Li, W. P. Zhang, X. W. Guo, E. J. M. Hensen, Q. H. Yang, C. Li, J. Phys. Chem. C, 2010, 114, 6553-6559.

[21] S. Du, Q. Sun, N. Wang, X. Chen, M. Jia, J. Yu, J. Mater. Chem. A, 2017, 5, 7992-7998.

[22] A. Silvestre-Albero, A. Grau-Atienza, E. Serrano, J. García-Martínez, J. Silvestre-Albero, Catal. Commun., 2014, 44, 35-39.

[23] S. T. Tsai, P. Y. Chao, T. C. Tsai, I. Wang, X. Liu, X. W. Guo, Catal. Today, 2009, 148, 174-178.

[24] D. Verboekend, J. Pérez-Ramírez, Chem. Eur. J., 2011, 17, 1137-1147.

[25] D. Wang, L. Zhang, L. Chen, H. Wu, P. Wu, J. Mater. Chem. A, 2015, 3, 3511-3521

[26] B. Wang, M. Lin, X. Peng, B. Zhu, X. Shu, RSC Adv., 2016, 6, 44963-44971.

[27] B. Wang, X. Peng, W. Zhang, M. Lin, B. Zhu, W. Liao, X. Guo, X. Shu, Catal. Commun., 2017, 101, 26-30.

[28] X. Fang, Q. Wang, A. Zheng, Y. Liu, L. Lin, H. Wu, F. Deng, M. He, P. Wu, Phys. Chem. Chem. Phys., 2013, 15, 4930-4938.

[29] Y. Yang, J. Ding, B. Wang, J. Wu, C. Zhao, G. Gao, P. Wu, J. Catal., 2014, 320, 260-169.

[30] L. Xu, D. D. Huang, C. G. Li, X. Ji, S. Jin, Z. Feng, F. Xia, X. Li, F. Fan, C. Li, P. Wu, Chem. Commun., 2015, 51, 9010-9013.

[31] L. Xu, J. Ding, Y. Yang, P. Wu, J. Catal., 2014, 309, 1-10.

[32] C. Liu, J. Huang, D. Sun, Y. Zhou, X. Jing, M. Du, H. Wang, Q. Li, Appl. Catal. A, 2013, 459, 1-7.

[33] D. G. Huang, X. Zhang, B. H. Chen, Z. S. Chao, Catal. Today, 2010, 158, 510-514.

[34] C. Li, G. Xiong, J. Liu, P. Ying, Q. Xin, Z. Feng, J. Phys. Chem. B, 2001, 


\title{
Graphical Abstract
}

Chin. J. Catal., 2020, 41: 1109-1117 doi: 10.1016/S1872-2067(20)63546-X

Crossed intergrowth triggered TS-2 microsphere: Formation mechanism, modification and catalytic performance

Hao Xu, Wenwen Tian, Liping Xu, Xin Jin, Teng Xue, Li Chen, Mingyuan He, Peng Wu*

East China Normal University

TS-2 microspheres, composed of crossed intergrown nanocrystals, was prepared by carefully controlling the synthetic condition, which served as promising catalyst for the industrial ammoximation reactions.

105, 2993-2997.

[35] J. S. Reddy, S. Sivasanker, P. Ratnasamy, J. Mol. Catal., 1991, 69, 383-392.

[36] C. Wu, Y. Wang, Z. Mi, L. Xue, W. Wu, E. Min, S. Han, F. He, S. Fu, React. Kinet. Catal. Lett., 2002, 77, 73-81.

[37] J. Le Bars, J. Dakka, R. A. Sheldon, Appl. Catal. A, 1996, 136, 69-80.
[38] Y. Zuo, W. Song, C. Dai, Y. He, M.Wang, X. Wang, X. Guo, Appl. Catal. A, 2013, 453, 272-279.

[39] A. Zecchina, F. Geobaldo, C. Lamberti, S. Bordiga, G. Turnes Palomino, C. Otero Arean, Catal. Lett., 1996, 42, 25-33.

[40] X. Lu, H. Xu, J. Yan, W. J. Zhou, A. Liebens, P. Wu, J. Catal., 2018, $358,89-99$.

\section{TS-2微球的形成机理、后处理修饰和催化应用}

徐 浩, 田文文, 徐丽萍, 金 金金, 薛 腾, 陈 丽, 何鸣元, 吴 鹏 ${ }^{*}$ 华东师范大学化学与分子工程学院, 上海市绿色化学与化工过程绿色化重点实验室, 上海200062

\begin{abstract}
摘要: 钛硅分子篮材料是一种优异的选择性氧化反应催化剂, 能在温和的条件下活化双氧水, 并且只副产水, 构建了一系 列绿色高效的催化反应体系, 已成功地应用于环已酮氨肜化、丙烯环氧化等工业过程. 但是, 工业上使用的钛硅分子篎通 常需要经过成型, 这避不可免地引入惰性的粘结剂甚至会造成堵孔, 导致催化剂的活性降低. 因此, 直接合成具有微米尺度 的钢硅分子笁材料有望解决上述问题. 本文通过控制晶化条件直接水热合成了一种由初级粒子经晶间交叉生长堆积成的 TS-2微球, 详细考察反应条件, 包括季铵盐模板剂的用量、 $\mathrm{H}_{2} \mathrm{O} / \mathrm{Si}$ 比、醇的存在与否和晶化温度等的影响, 发现反应体系保 持高的碱度、静态晶化以及体系无醇是TS-2微球形成的关键因素. 进一步地对TS-2晶化过程进行详细跟踪考察, 发现常规 TS-2纳米颗粒与TS-2微球在晶化初期均会形成无定形微球. 随着晶化的进行, 无定形相晶化成为TS-2纳米晶粒, 是一级粒 子, 相互堆积形成次级粒子. 较高的碱度使得TS-2微球的一级粒子以交叉生长的方式堆积, 从而保证微球形貌在整个晶化 过程中得以保持; 而TS-2纳米颗粒中初级粒子以平行的方式堆积, 无法保持初始的微球形貌, 最终形成纳米尺度的聚集体. 扫描电镜和透射电镜照片均证实了TS-2微球中初级粒子成交叉生长的方式堆积. TS-2微球催化剂经模板剂、氯化铵和哌 啶组成的混合溶液水热处理, 发生了溶解-再晶化过程, 外比表面积从 148 增至 $176 \mathrm{~m}^{2} \mathrm{~g}^{-1}$, 介孔孔容从 $0.16 \mathrm{~cm}^{3} \mathrm{~g}^{-1}$ 升至 0.24 $\mathrm{cm}^{3} \mathrm{~g}^{-1}$; 成功引入介孔的同时, 仍能保持TS-2微球形貌以及Ti活性中心的四配位状态. 经哌啶混合溶液处理后得到的 MS-TS-2-PI在环己酮肜化反应中表现出优于MS-TS-2微球的催化性能, 环己酮转化率从18.6\%升至 $91.4 \%$, 环己酮肜选择性 从 $86.6 \%$ 升至 $97 \%$. 再经 $\mathrm{Na}^{+}$离子交换可以消除骨架中的 $\mathrm{Si}-\mathrm{OH}$, 增强了骨架的疏水性, 进一步地提高了其在环己酮肜化反 应中的催化性能; 环己酮转化率和环己酮肜选择性均> $99 \%$. 在环己酮肜化连续反应中, TS-2微球表现出稳定的催化性能, 使用寿命达到 90 h, 与工业TS-1催化剂相当, 是一种具有工业前景的催化剂.
\end{abstract}

关键词: 钢硅分子篮; TS-2 微球; 交叉生长; 肜化反应; 后处理

收稿日期: 2019-09-21. 接受日期: 2019-11-16. 出版日期: 2020-07-05.

*通讯联系人. 电话/传真: (021)62232292; 电子信箱: pwu@chem.ecnu.edu.cn 基金来源：国家自然科学基金(21533002, 21603075, 21872052); 科技部重大项目(2016YFA0202804).

本文的电子版全文由Elsevier出版社在ScienceDirect上出版(http://www.sciencedirect.com/science/journal/18722067). 